\title{
Observations from the Folkestone, UK, earthquake of 28 April 2007
}

S.L. Sargeant ${ }^{1}$, P.J. Stafford ${ }^{2}$, R. Lawley ${ }^{3}$, G. Weatherill ${ }^{4}$, A-J.S. Weston ${ }^{5}$, J.J. Bommer ${ }^{2}$, P.W. Burton $^{4}$, M. Free ${ }^{6}$, R.M.W. Musson ${ }^{1}$, T. Kuuyuor ${ }^{7}$, and T. Rossetto ${ }^{8}$

${ }^{1}$ British Geological Survey, Murchison House, Edinburgh, EH9 3LA, UK

${ }^{2}$ Imperial College London, Department of Civil \& Environmental Engineering, London, SW7 2AZ, UK

${ }^{3}$ British Geological Survey, Kingsley Dunham Centre, Keyworth, Nottingham, NG12 5GG, UK

${ }^{4}$ University of East Anglia, School of Environmental Science, Norwich, NR4 7TJ, UK

${ }^{5}$ University of Southampton, GeoData Institute, Southampton, SO17 1BJ, UK

${ }^{6}$ Arup, 13 Fitzroy Street, London, W1T 4BQ, UK

${ }^{7}$ Cranfield University, Department of Defence Management and Security Analysis, Shrivenham SN6 8LA, UK

${ }^{8}$ University College London, Department of Civil Engineering, London, WC1E 6BT, UK

* Corresponding author: E-mail p.stafford@imperial.ac.uk, Phone +44 (0) 2075946030

\section{INTRODUCTION}

Earthquakes in Britain are usually minor with respect to damage. However, the Folkestone earthquake (4.3 $\mathrm{M}_{\mathrm{L}}, 4.0 \mathrm{Mw}$ ), which occurred on the south-eastern coast of England (Figure 1) on 28 April 2007 at 07:18 UTC (08:18 BST) caused significant damage. One person was injured by falling masonry and emergency procedures were invoked by Shepway District Council in order to deal with the effects of the earthquake. This is the first time that emergency procedures have been invoked for a British earthquake. Around 60,000 homes lost power for 85 minutes due to tripping of two high-voltage transformers.

The epicentre of the earthquake, latitude $51.102^{\circ} \mathrm{N}$ and longitude $1.169^{\circ} \mathrm{E}$ (Ottemöller et al., 2008), locates very close to Folkestone (Figure 1a-c). Ottemöller et al. (2008) determine a depth of around $6 \pm 3 \mathrm{~km}$ from UK and European short-period and broadband data. The focal mechanism, shown in Figure 1c, indicates normal faulting with a significant component of strike-slip on either a northnorthwest to south-southeast trending or east-northeast to west-southwest trending plane (Ottemöller et al., 2008). The earthquake was followed by nine aftershocks $\left(1.0-1.8 \mathrm{M}_{\mathrm{L}}\right)$, which occurred up to 5 May 2007. None of these were felt.

A compendium of observations from the Folkestone earthquake is presented here. This includes analysis of the first 'strong'-motion record from a British earthquake, a description of the damage 
and an investigation of how the distribution of damage may relate to the distribution of unconsolidated deposits, and the results of the macroseismic survey for the earthquake. Assignment of maximum intensity, and its spatial extent, provoked a lively debate among the authors, which is also documented.

\section{SEISMICITY OF THE FOLKESTONE AREA}

There is a distinct east-west divide in terms of the distribution of seismicity in the UK. Most activity is concentrated in western Scotland, north-western England, Wales, the Midlands and Cornwall (Figure 1a). In the eastern part of the country, levels of seismicity are lower. However, this is also where some of the more significant British earthquakes have occurred, e.g., 7 June 1931 Dogger Bank (6.1 $\left.\mathrm{M}_{\mathrm{L}}\right), 22$ April 1884 Colchester $\left(4.6 \mathrm{M}_{\mathrm{L}}\right)$.

The Folkestone event is of particular interest because of past earthquakes in the Dover Straits area in $1382,1580,1776$ and 1950 (Figure $1 b)$. The 1382 earthquake $\left(\mathrm{M}_{\mathrm{L}}>5.5\right)$ caused minor damage in London. Its epicentre is relatively well constrained for this period by felt reports (Musson, 1994; Melville et al., 1996). The 1580 earthquake $\left(\mathrm{M}_{\mathrm{L}} \sim 5.75\right)$ was located between Dover and Calais and caused widespread damage in Kent, Pas de Calais and the Low Countries, and London, where two children were killed (Neilson et al., 1984; Melville et al., 1996). The 1776 and 1950 events occurred in a similar area. Since earthquakes in this area could have serious implications for London, a key question arising from the Folkestone earthquake was 'to what extent has its occurrence increased or decreased the probability of a larger earthquake in the Dover Straits causing regional damage?' Although it is impractical to consider this quantitatively from the point of view of stress distribution, it remains a valid topic of speculation. This is particularly the case given the risk of damage in a capital city with a low level of preparedness (the last time earthquake damage occurred in London was 1750).

\section{ANALYSIS OF 'STRONG’MOTION DATA}

One accelerogram of the Folkestone earthquake was recorded at station TFO $\left(51.1135^{\circ} \mathrm{N}\right.$, $1.1409^{\circ} \mathrm{E}$ ), just over $5 \mathrm{~km}$ north-northwest from the epicentre of the event (Figure 1c) and just under $4 \mathrm{~km}$ from the region of concentrated damage in Folkestone. The bedrock at the station is chalk and the superficial geology consists of sandy clay with flints. This information is taken from the bedrock and superficial geology maps of the area and is not based upon any site-specific investigation [although boreholes in the area suggest that superficial sediments are of the order of 2$18 \mathrm{~m}$ thick (Ottemöller et al., 2008)]. The accelerograph is located in free-field conditions and is an 
Integra 3JLA10 with a flat response to acceleration up to approximately $25 \mathrm{~Hz}$ and a sampling rate of $100 \mathrm{~Hz}$. While the recording is not significant from a global strong-motion perspective, this recording is significant for the UK in that it captures the strongest acceleration ever recorded of $0.118 \mathrm{~g}$ on the north-south component. The horizontal acceleration, velocity and displacement timehistories for the accelerogram are shown in Figure 2 along with the annotated peak value corresponding to each trace. It is clear that the relatively strong peaks that may be observed in the acceleration and velocity traces are isolated spikes that are not overly representative of the overall strength of the shaking at the TFO site. A peak acceleration, velocity and displacement of $0.036 \mathrm{~g}$, $0.53 \mathrm{~cm} / \mathrm{s}$ and $0.02 \mathrm{~cm}$ respectively were observed on the vertical component. The instrumental recordings of the horizontal components may be used to infer an anticipated level of damage as quantified by a macroseismic intensity scale. Using the relationship of Wald et al. (1999), the peak ground accelerations suggest that Modified Mercalli intensities of around V-VI (5.6-5.9) should have been experienced in the vicinity of the TFO station. The proximity of the TFO station to both the located epicentre and the town of Folkestone further suggests that similar levels of intensity would be expected to occur in Folkestone itself.

Elastic acceleration response spectra for a damping ratio of 5\% were calculated and are plotted in Figure 3. The spectra have peak amplitudes occurring at periods of roughly 0.1 seconds and have very weak spectral amplitudes at moderate to long periods, both attributes reflecting the dominance of high-frequency components expected in recordings of small earthquakes at short source-site distances. The amplitude of the geometric mean spectrum with respect to the spectra of the two orthogonal components also indicates that there is no strong polarization of the ground motion at the TFO site. Given the magnitude of the earthquake and the small rupture dimensions that are associated with such events, the lack of polarization is to be expected.

Ground conditions at the recording station are inferred to correspond to ground type ' $\mathrm{B}$ ' under the Eurocode 8 classification system (CEN, 2004). A comparison of the geometric mean of the recorded elastic acceleration response spectra with that of the Type II Eurocode 8 (EC8) spectra for different damping levels is presented in Figure 4. For this comparison the EC8 spectra are anchored to the geometric mean of the peak ground accelerations observed at the TFO site. As the site response is directly incorporated into the observed motions the site class factor, $\mathrm{S}$, is removed from the EC8 specifications while still adopting the relevant corner periods for site class B (S is a constant factor across all periods and therefore has no effect on the spectral shape). Figure 4 shows that at very short periods the spectral shape of EC8 is a reasonable, albeit unconservative, approximation to the observed spectra, while at intermediate to long periods the EC8 spectrum is 
much stronger. Such a disagreement between spectral shapes is to be expected given that the EC8 spectra are based upon spectral shapes corresponding to larger earthquakes: the Type II spectrum in EC8 was calibrated to recordings from events of $\mathrm{M}_{\mathrm{S}} \sim 5.5$ (Rey et al., 2002). This difference in spectral shape supports the argument that the use of fixed spectral shapes for the specification of seismic design actions should at least account for the differences in magnitude scaling in a more thorough manner than that currently proposed in EC8 (Bommer and Pinho, 2006).

The comparison of the spectra in Figure 4 suggests that the use of the EC8 spectrum for engineering design in the United Kingdom is likely to be conservative in most cases. However, for highly acceleration-sensitive structures (very short-period structures), or for high-frequency non-structural components such as machinery, design according to the EC8 spectral shape may be unconservative. For cases such as these, spectral ordinates at levels of damping other than the commonly assumed $5 \%$ may be relevant. It is therefore instructive to assess the performance of the EC8 damping correction factors with respect to the recorded spectra from the Folkestone earthquake. The EC8 damping correction factors are based upon the work of Bommer et al. (2000) and take no account of the influence of duration that was later identified by Bommer and Mendis (2005). Recently, this influence has been quantified for spectral displacements by Stafford et al. (2008) enabling comparisons to be made amongst the observed spectral ratios from the Folkestone recording, the EC8 provisions, and the new duration-dependent relationships. The small-magnitude Folkestone earthquake caused very short significant durations (Bommer and Martínez-Pereira, 1999), $D_{5-95 \%}$, of 2.58 and 3.11 seconds for the North-South and East-West components respectively. The comparison between the various spectral ratios is shown in Figure 5 by plotting period using both logarithmic and linear axes. For these comparisons the geometric mean of the observed horizontal significant durations (2.83 seconds) was used as the input into the model of Stafford et al. (2008). The figure shows that the EC8 proposal matches the ratios from the Folkestone accelerogram very well for periods up to about one second corresponding to the acceleration and velocity dominated regions of the spectra. However, as one moves to longer periods the EC8 correction factors are significantly different from those of the Folkestone recording. The duration-dependent ratios of Stafford et al. (2008) perform much better over this period range but are still not able to replicate the observed ratios of the Folkestone recording.

When making these comparisons it must be kept in mind that both the EC8 and Stafford et al. (2008) proposals are being applied outside of the magnitude range for which they were derived as well as the fact that the comparison is being made with respect to a single observation. However, the comparisons do suggest that the influence of duration on damping correction factors is an 
important consideration for seismic design in the UK where small magnitude earthquakes, with short durations, dominate the seismic hazard.

It may seem unusual that no comparison has been made between the observed spectral amplitudes and predictions from applicable empirical ground-motion models for the region. The main reason why we have refrained from making such a comparison is that there are not really any robust empirical ground-motion models for this region and this type of earthquake scenario. Recent seismic hazard analyses that have been conducted for regions including the UK, such as the study of Bungum et al. (2000), have adopted equations from continental Europe (i.e., Ambraseys et al., 1996) or from the central and eastern US (Toro et al., 1997). Earlier studies such as Musson and Winter (1997) made use of the intraplate equations of Dahle et al. (1990) or modifications thereof (Musson et al. 1994). Given that we have only one record and that the predicted ground-motions corresponding to this scenario are highly uncertain there is little sense in looking to draw conclusions from comparisons made between the two. It may be that the observed recording matches the predictions of a particular equation very well but this does not mean that the recorded motion is typical anymore than it means that the ground-motion model is valid. Furthermore, the most recent prediction equations for active crustal parts of Europe including both Ambraseys et al. (2005) and Akkar and Bommer (2007a,b) are applicable for moment magnitudes greater than or equal to 5.0. It has long been stipulated by ground-motion modellers that their equations should not be extrapolated beyond the range of predictor variables from which they were developed. The potential impact that such a practice may have has recently been investigated by Bommer et al. (2007) and indicates that not only should one not extrapolate but one should also be cautious about the quality of predictions associated with scenarios near the peripheries of the range of predictor variables used in the development of empirical equations.

As with the damping ratio considerations discussed previously, the issue of extrapolating empirical ground-motion models is of great importance for the specification of seismic design actions in the UK. The sheer lack of accelerograph recordings in the UK dictates that foreign empirical relationships, developed for other countries or regions, will inevitably be used for seismic hazard analyses conducted in the UK. Most of these equations are developed for regions of greater seismic activity and the focus during the development of these equations is therefore on ensuring that the scaling of genuinely strong ground-motions is properly captured. This significant difference in focus results in empirical models developed for moderate-to-large magnitude events being unreliable when extrapolated below their lower limit of applicability (Bommer et al., 2007). On the other hand, as events like the Folkestone earthquake gradually contribute to the repository of 
accelerograms recorded in the UK care must be taken when models developed on the basis of these recordings of small earthquakes are then extrapolated to higher magnitudes for the purpose of seismic hazard analyses. In this case the underlying magnitude scaling of the ground-motions over the upper ranges of magnitudes that are considered in the hazard analyses is unlikely to be properly captured and will most likely lead to an overestimation of ground motions (Bommer et al., 2007). Although the accelerogram from the Folkestone earthquake, together with the existing databank of UK recordings, may not be suitable for the derivation of a national ground-motion prediction equation for the United Kingdom, such records can be very useful in seismic hazard analysis in terms of guiding the selection and/or adjustment of predictive equations from other regions (e.g., Cotton et al., 2006).

\section{DAMAGE SURVEY}

\section{Assessment of Building Stock}

Damage from the earthquake was concentrated in the Foord district of the coastal town of Folkestone, close to the epicentre. The worst affected areas are dominated by two and three storey un-reinforced brick built residential properties of the Late Victorian / Early Edwardian period (1870-1919) and the inter-war period (1920-1939). Edwardian construction is characterised by solid walls of fired clay brick, bonded with lime or cement-lime mortar with timber rafters and floor joists that are generally not tied to the brickwork. Large brick chimneys are also a feature of this period, and these have been shown to be a particularly vulnerable feature during earthquakes (Ove Arup, 1993). Solid walls of fired clay bricks were still the main construction method during the inter-war period but by the 1930s the mortar in common use was a mixture of cement and lime, which generally improved the strength of walls and chimneys. Terraced houses were still dominant during this period but semi-detached and detached properties were also becoming more widespread (Ove Arup, 1993), although within the areas visited during the damage surveys, detached properties are rare.

Building condition also strongly influences vulnerability. Folkestone's building stock, when compared with the national UK profile, is generally older with a higher proportion of pre-1920 properties (Shepway District Council, 2001). These older properties, particularly terraces and those in the private rented sector are generally found to be less well maintained than other age, style and tenure types. Residences in the areas of Folkestone visited during the damage survey can generally be considered to be among these older, privately rented and less well maintained properties. 


\section{Observed Damage}

Several independent, but largely overlapping, surveys of the building damage in Folkestone were undertaken after the earthquake. Initial surveys were conducted by the media, the local council and engineers from Imperial College London and Ove Arup within a few hours of the earthquake occurrence. These initial surveys were then followed up on 1 May 2007 by structural engineers from University College London and by a delegation of seismologists from the British Geological Survey (BGS), the University of East Anglia, and Southampton and Cranfield universities. The BGS team also inspected damage throughout 2 May 2007.

The main areas of damage in Folkestone are marked in Figure 6. This map is based on the damage lists maintained by Shepway District Council during their response to the earthquake and encompasses all but one or two sites visited by the reconnaissance teams. Shepway District Council's building control team assigned properties to one of five categories corresponding to the priority given to the need for action based on the level of risk posed to the public by the damage. Category 1 was defined as "Unoccupiable... posing high level of risk to the public. Immediate action required". 'Unoccupiable' here should not be read literally but should rather be interpreted within the context of the very stringent Health and Safety culture of the UK. Category 2 damage was similar to Category 1 but with a lower risk of collapse or injury. Category 3 covered reports of cracks. Category 4 indicated that the building had been assessed and made safe (it may have been assigned to Category 1 to start with), and Category 5 indicated an unconfirmed report of damage. To the best of our knowledge, this is the first occasion that any buildings in the UK have been so designated as a result of earthquake damage in order to implement a public Health and Safety based response.

The initial reconnaissance surveys conducted on the day of the event and up until 1 May relied heavily upon word-of-mouth. However, the subsequent surveys targeted Category 1 properties that were on the council's list as at 21:00 UTC on 28 April 2007. The amalgamated findings of these surveys are briefly detailed in what follows.

By far the most common form of damage observed was chimney damage ranging from moderate to partial collapse. In most roads chimney damage was observed in 10-20\% of buildings (e.g., Black Bull Road), however in some roads (e.g., northern end of Marshall Street, Broadmead Road) this damage rate rose to $60-70 \%$. The chimneys consist of brick stacks on which multiple cylindrical clay chimney pots are mounted with mortar. These heavy clay chimney pots were commonly seen to dislodge as a result of the ground shaking, often together with bricks in the chimney stacks. The 
extent of chimney damage varied significantly among chimneys located in close proximity. The majority of damage seemed to occur in chimneys that had been poorly maintained and that had either lost mortar or had suffered some sulphur intrusion. However, this was not always the case. Some chimneys that had been re-pointed with cement mortar, which tends to be less flexible than the original lime-mortar, were also seen to be damaged. The failure of chimneys was also seen to cause secondary damage to roofs. In most cases this was limited to the removal of roof tiles (commonly seen in the lea of falling chimney pots) and in rare cases damage to the roof structure.

Additional non-structural damage consisted of damage to a gable-end wall in Black Bull Road and the cracking of plaster in some houses. Interior plaster cracking was mainly seen to occur along joints of ceiling plaster board panels. Diagonal cracking of plaster was also observed to occur above door frames. All such damage is essentially cosmetic in nature and has no impact upon the integrity of the structure.

Some light structural damage was seen in a very few locations, mainly on Radnor Park Road and Broadmead Road. Here, buildings were observed to have suffered some vertical cracking of walls and lintels. This can be regarded as the most severe form of direct earthquake damage observed in Folkestone.

To the west and south of Radnor Park (Figure 6-Marker 'A'), chimney pots were dislodged on isolated properties (1930s-style three-storey detached houses), but not fallen. Damage was more extensive in the region to the east of Radnor Park, an area characterised by two- and three-storey 1930s' semi-detached housing. In these roads most properties exhibited chimney damage. In some cases this was principally in the form of dislodged bricks or extensively cracked chimney stacks. There were many properties, however, for which the chimney stack had collapsed, either partially or in its entirety above the roof level. Rather than chimneys fracturing at the roofline, the full body of the chimney stack fractured and disintegrated. For many of these houses, the impact of falling bricks was sufficient to dislodge and break tiles on both the property and its neighbour's roof (Figure 7a), thus increasing the number of houses damaged. Cracks (2-4 mm wide) were evident in plasterwork and brickwork of exterior main walls on some of these properties (Figure 7b).

North of Pavilion Road and Radnor Park Road (Figure 6 - marker 'D') are smaller residential streets lined with terraced housing. Despite many reports of damage on these roads, it was less evident on the exterior of these buildings than in the semi-detached properties closer to Radnor Park. In this area, most of the chimney stacks remained intact though minor cracking was observed 
in the exterior plasterwork. This style of terraced housing is typical of the region east of and parallel to Black Bull Road (Figure 6 - marker 'E'). The density of damage was relatively high in this area with a large proportion of houses in these roads exhibiting chimney damage. Scaffolding had been erected on many of these properties and remedial action taken to prevent collapse of the chimney stack.

Larger roads lined by a mixture of residential and commercial properties and running southeast from the town centre to the harbour were also inspected. A three storey residential apartment building on Grace Hill (Figure 6 - marker ' $F$ ') suffered exterior damage in the form of a crack in the wall $10-15 \mathrm{~mm}$ wide extending through the roof line (Figure $7 \mathrm{c}$ ). Towards the harbour, along Tontine Street and Tram Road (Figure 6-marker ' $G$ ') there were few reports of damage, and none in the harbour itself. No damage was reported to the railway line or any associated viaducts and tunnels.

In the east of the town, along Dover Road (Figure 6 - marker 'I'), the density of damaged buildings was not as great as in the roads to the west although there were isolated incidences of significant chimney damage. Isolated incidences of damage were also reported for properties in smaller roads connected to Dover Road. These were mainly in end-of terrace houses which had cracks in the gable end. Stuart Road, a small cul-de-sac of terraced housing (Figure 6 - marker 'J') suffered significant damage with nearly one third of the chimney stacks either partially or entirely collapsed to roof level (Figure 7d).

The highest density of damaged properties occurred in the region around Canterbury Road. Of particular note are the 1930s style terraced properties along Sidney Street and Marshall Street (Figure 7e), on which there were many (consistent with MSK and EMS macroseismic definitions of “many”) examples of partial and full collapse of chimney stacks. Vertical cracks tens of millimetres wide were observed in those chimney stacks that had not collapsed. In contrast to the terraced housing in the surrounding roads, Canterbury Road itself is characterised by semi-detached threeand four-storey 1930s style properties. Damage to these buildings was mostly a result of partial collapse of chimney stacks, affecting nearly half of the properties. Generally these buildings were in good condition at the time of the earthquake.

The streets around the junction between Black Bull Road, Radnor Park Road and Foord Road (Figure $6-{ }^{\prime} N^{\prime}$ ) are characterised by late Victorian and early $20^{\text {th }}$ Century residential terrace housing. Damage to chimney stacks was, again, mostly in the form of partial collapse with some 
such collapses extending down to as far as the roof level. The density of damaged properties was not as high in this region compared to the Radnor Park and Canterbury Road areas despite the apparently lower level of maintenance and condition of some of the buildings. Outside the Foord district of Folkestone, incidences of damage were rare and isolated.

In interpreting structural damage to houses in Folkestone, care must be taken to consider their history and the possible presence of existing damage. Folkestone was subjected to bombing in the Second World War and it may be that some of the structural cracking may have first initiated during this era, and was then aggravated by the earthquake ground-shaking. Such knowledge of the local history proved important when surveying the only school to be damaged by the earthquake, Harvey Grammar School. This school is located about $2 \mathrm{~km}$ west of the main areas of damage and was built in 1912 to have symmetrical façades. During WWII the western façade was bombed and later rebuilt in 1945. The "plane of weakness" locally created between the old school building and the newer façade partially explains why this particular section suffered cracking along its height and especially at its connection with the old building.

The only case of Moderate damage was observed in the building adjoining Grace Independent Baptist Church and School on Grace Hill. This building was cordoned off and condemned as it was reported to have suffered severe internal damage. A vertical crack was observed along the front of the building. Some possible torsion of the building was observed, although its severity was difficult to determine from rapid visual inspection. The authors consider this building to be particularly susceptible to earthquake damage due to its irregularity in elevation and location, i.e., it is built on a slope so that the front is 3 storeys and the back is 4 storeys high.

No recently constructed masonry buildings were seen to be damaged by the earthquake. This is to be expected in a small earthquake and highlights the importance of good construction and maintenance in helping resist earthquake-induced ground-shaking.

\section{THE ROLE OF SITE EFFECTS}

The possibility that superficial geology may have influenced the spatial distribution of damage in Folkestone was investigated. Figure 8a shows the distribution of all damaged properties reported to the local District Council. The current 1:50,000 scale geological map of the area (Figure 8b) indicates superficial deposits associated with the River Pent, which is now culverted extensively beneath Folkestone, partial infilling of minor tributary valleys and mantling of the areas between adjacent streams. Additional thin tracts of accumulated soil and hill wash material associated with 
the River Pent and its tributaries may also be present. However, such deposits are difficult to map across urban areas using traditional methods as they are easily obscured by man-made construction. Clearly, the 50k map does not tell the whole story. However, very simple terrain analysis can create indicative maps of where these superficial deposits may occur, which can then be verified through targeted surveying. Although terrain models do have their flaws and are a poor substitute for a detailed ground-based survey, they do offer a rapid 'overview' of the possible locations of poorly consolidated near-surface accumulated deposits. Our aim here was to use terrain analysis to determine whether the distribution of damage was related to the distribution of unconsolidated superficial deposits.

\section{Derivation of the accumulated material model}

The accumulated material model was derived from the Nextmap Digital Terrain Model (NDTM; Intermap) for an area that covers the location of TFO and Folkestone (Figure 8c). Standard algorithms for calculating the surface, planform and profile curvatures (Zeverbergen and Thorne, 1987) were used. The planform curvature is the curvature of a hill measured along a height contour. The profile curvature is the amount of curvature as you move down slope (Shary et al., 2001). The NDTM has a nominal cell size of $5 \mathrm{~m}$. Using bilinear resampling, the grid was resampled for cell sizes of $10 \mathrm{~m}, 25 \mathrm{~m}$ and $50 \mathrm{~m}$. The resampling creates a smoothed and generalised land surface with reduced surface noise from trees and urban features. Creating surfaces for three different grid cell sizes allowed the effect of NDTM complexity on the overall results to be investigated. Planform curvature $\left(p l_{\text {curv }}\right)$ and profile curvature $\left(p r_{\text {curv }}\right)$ were determined from the NDTM from which the overall curvature $\left(\right.$ tot $\left._{\text {curv }}\right)$ was obtained:

$$
\text { tot }_{\text {curv }}=p l_{\text {curv }}-p r_{\text {curv }}
$$

Output from the curvature analysis (i.e., tot $_{c u r v}$ ) provides a continuous grid of positive or negative values across the study area. Positive values represent areas of convex-upward landforms (interfluves) where unconsolidated deposits would be expected to erode from. Negative values represent areas of concave-upward landforms (valleys) where unconsolidated deposits would be expected to accumulate. These areas of negative overall curvature are shaded grey in Figure $8 \mathrm{c}$. Note that the results obtained here are purely indicative with regard to superficial geology and do not constitute site-condition maps of the type derived by Wald and Allen (2007) directly from topographic data.

The validity of each of the accumulated material models (i.e., $10 \mathrm{~m}, 25 \mathrm{~m}$ and $50 \mathrm{~m}$ ) was assessed by comparing the results to the existing geological map (Figure $8 \mathrm{~b}$ ) and a limited number of geological boreholes in the Folkestone area. A qualitative judgement was also made as to whether 
the geometries of the deposits in the model reflect a natural system. The 10-meter model (not shown) is characterised by an almost uniform distribution of potential accumulation sites across the Folkestone area and it is difficult to identify any features in common with the geological map. Furthermore, the results appear to be subject to data acquisition and processing artefacts with manmade structures such as the mainline railway, Channel Tunnel railway link and major roads and motorways causing edge-effects and false surface curvature. At 25 meters (also not shown), correlation with the mapped geology, although improved, remains relatively poor. There is some correlation with mapped deposits in the rural area north of Folkestone but the urban area is still affected by cultural and processing effects and the River Pent valley is poorly defined. The 50meter model (Figure 8c) shows a strong visual correlation with the mapped geology north of Folkestone. In the town, the River Pent and its tributaries are clearly delineated. There is also a weak correlation between the modelled and mapped colluvial deposits around the north-eastern area of the town. However, the mainline railway remains a problematic feature.

The 50-meter model is preferred and indicates potential for a wider spread of unconsolidated accumulated material than suggested by the 50k geological map. In the absence of ground-truthing, this result must be considered preliminary. However, it is possible to compare the incidences of damage with the superficial geology map in Figure $8 \mathrm{~b}$ and the map showing potential areas of sediment accumulation in Figure 8c. The results in Table 1 indicate that a higher proportion of the damaged properties may be underlain by unconsolidated accumulated deposits than indicated by the geological map (59\% as opposed to $12 \%$ ). However, it is also evident that whilst there may be some degree of correlation between the inferred presence of unconsolidated material and building damage, a significant number of properties must also be founded in bedrock or weathered bedrock. The significance of this correlation must be investigated using traditional ground-truthing techniques but the issue of building vulnerability must be addressed fully too.

Ottemöller et al. (2008) used microtremor recordings from TFO to compute the H/V spectral ratio for this station. Two significant peaks are identified at $0.4 \mathrm{~Hz}$ and $3.9 \mathrm{~Hz}$ with a smaller, less significant, peak at $17 \mathrm{~Hz}$. Ottemöller et al. (2008) estimate that the peak at $17 \mathrm{~Hz}$ corresponds to an impedance contrast at around $11 \mathrm{~m}$ depth, which may coincide with the base of the superficial deposits. The geological map in Figure 8b clearly shows that TFO is founded on superficial deposits. The picture from the accumulated material model is less clear and highlights the importance of ground truthing the results, as well as determining depth to bedrock, which is not straightforward. Whether the peaks in the $\mathrm{H} / \mathrm{V}$ spectral ratio are indicative of ground-motion amplification in the damaged area of Folkestone is unknown. 


\section{MACROSEISMIC SURVEY}

Since December 2005, macroseismic surveys for British earthquakes have been conducted using an online questionnaire. The survey is implemented as a series of five pages and is based on the sample questionnaire published in the Manual of Seismological Observatory Practice (Musson, 2002). Data are collected in standard and free form. The standard form data are used in an automatic intensity assessment programme (Musson, 2006). This programme seeks to mimic human judgement and uses a process of elimination to assign intensity. A minimum of five reports are required per grid square (measuring $5 \times 5 \mathrm{~km}$ ) for an assessment of intensity to be made; otherwise the earthquake is assigned as either 'felt' or 'not felt' in that grid square. Free form data are retained for later consultation. In England, where the majority of residential building stock consists of two and three storey brick constructions, all buildings are assumed to be of vulnerability class B as defined in the European Macroseismic Scale (EMS-98; Grünthal, 1998). EMS-98 considers unreinforced masonry and brick as class B, though it does recognise such buildings can loosely span classes A-B-C depending on the quality of the structure.

For the Folkestone earthquake, 1077 replies were received in four days, mostly from south-eastern England. There are a total of 234 grid squares. Intensities are shown in Figure 9. The earthquake was reportedly felt as far north as Norwich, approximately $180 \mathrm{~km}$ from the epicentre. The western limit of the felt area is uncertain and depends on whether these observations are genuine or not. The earthquake was very little felt in London (probably 2 EMS). The bulk of the information comes from Kent. The earthquake was also surprisingly little felt in France although seven observations were provided by Bureau Central Seismologique Français. Most of the felt area is over the UK but it is anomalously small for an event of this magnitude when compared to the expected isoseismals calculated using average intensity attenuation for the UK (Musson, 2005; Figure 10). While isoseismals 5 and 6 are fairly well-predicted by the model, the expected area encompassed by isoseismal 4 is significantly larger than observed and larger again for isoseismal 3. Because the observed 2 EMS isoseismal is so poorly constrained, a comparison between it and the expected isoseismal is meaningless. Had this been a historical event, the magnitude may well have been underestimated from the felt reports; the macroseismic magnitude is $3.8 \mathrm{M}_{\mathrm{L}}$ from isoseismal 3 EMS, and 3.7 $\mathrm{M}_{\mathrm{L}}$ from isoseismal 4 EMS. Isoseismals are directed noticeably towards the northwest. The macroseismic depth is $5 \pm 2 \mathrm{~km}$ and is consistent with the instrumental estimate. 


\section{Maximum Intensity Assignment}

The maximum intensity $\left(I_{\max }\right)$ determined automatically from the intensity assessment programme was 8 , and this intensity was given in preliminary announcements before any field survey was carried out. As a general rule, a field survey should be carried out for automatically assigned intensities of 7 and above (Musson and Cecić, 2002), and the intensity assessment algorithm was not designed or expected to give definitive values from questionnaire data for higher intensities.

Each author has their own experience of building damage assessment and intensity assignment on which to draw. These individual perspectives led to a lively debate within the group, which we think is useful to present here. The issues and ambiguities that are discussed are specific to this earthquake and this locality. The debate centres on how one should interpret the EMS-98 scale. The issue of uncertainty with respect to intensity assignment caused by ambiguity in the data is wellknown and considered in detail in EMS-98. However, the issues raised by the Folkestone earthquake specifically in terms of the interpretation of chimney damage and its implications for maximum intensity assignment and the spatial extent of high intensity regions are worthy of discussion.

EMS-98 uses vulnerability classes to differentiate between structures. The most likely vulnerability class for the unreinforced masonry and brick structures in Folkestone is class B but class A and class C structures of this type are also possible, depending on building quality. Moderate nonstructural damage including some cracks, and partial collapse of chimneys transcribes into damage grade 2. There were examples in some streets of Folkestone of between a third and a half of properties suffering this damage classification, which thus transcribes into "many" observations of grade 2 damage. Given a typical type B set of masonry (brick) buildings, and taken in isolation, this points to 7 EMS (interpretation I).

One must also consider the relatively low quality of the building stock in this part of Folkestone and its impact on vulnerability along with the fact that evidence for grade 3 (moderate structural damage and heavy non-structural) damage to class B structures was elusory and there was certainly no damage of grade 2 to class $\mathrm{C}$ buildings, which are also indicators of intensity 7 . When chimney damage is considered as non-structural and specific references to chimneys in EMS-98 are ignored, most building damage in Folkestone can be classified as grade 1 (no structural damage, slight nonstructural damage): hair-line cracks in very few walls, fall of small pieces of plaster only, fall of loose stones from upper parts of buildings in very few cases. Accurately differentiating between structural and non-structural damage is important for assigning an appropriate damage grade since 
grade 2 damage is defined as slight structural damage with moderate non-structural damage. Whilst the partial collapse of chimneys certainly occurred extensively in Folkestone, the criterion of structural cracks in many walls was not observed except at a small number of properties on Broadmead Road and Radnor Park Road. However, even this damage would be at the lower bound of grade 2. Following this interpretation, it can be stated that 'many' buildings of vulnerability class B suffered damage of grade 1 at Radnor Park Road, Broadmead Road, Linden Crescent, Black Bull Road and Marshall Street, very few suffered damage of grade 2 and there was no damage to class $\mathrm{C}$ structures. Consequently, an intensity for this area of 6 EMS is assigned (interpretation II).

Therefore, a maximum intensity assessment of 6 EMS is assigned on the basis of the field survey of building damage alone if damage to chimneys is ignored. This still leaves the issue of corroboration of the intensity degree from other diagnostics if possible.

It is informative to consider the questionnaire data for Folkestone itself in relation to effects on people and household goods as well as any internal damage, since the field survey concentrated on examining mainly the exterior of buildings. Taking the data for the $5 \times 5 \mathrm{~km}$ square containing Folkestone, 200 replies were received. The data for the stronger effects are summarised in Table 2. For any question, the respondent could reply "yes it was observed at my location", "no it was not observed”, or “don't know/can't tell/no answer". The ratio of observers giving a positive response can thus either be construed as the proportion of respondents who answered the question who gave a positive answer (no answer is ignored) or the proportion of all respondents (no answer is treated as a negative response) - or somewhere in between. BGS practice is to consider all "don't know"s as negative answers.

The data in Table 3 shed some light on the interior effects of the earthquake: more than $50 \%$ of observers reported small cracks in plaster and about a third had large cracks. There were 83 reports of small falls of plaster and 17 of large falls. There were also many reports of cracks in brickwork. Also useful are effects like the fall of items such as books from shelves; these are unaffected by considerations of vulnerability or building type. Such falls were reported by nearly half the respondents (89 out of 200). The fall of small objects was reported by more than $75 \%$ of respondents. Furniture was shifted in 37 cases and actually overturned in nine cases.

Comparing these effects with the descriptions in EMS-98, they are compatible with intensity 7 EMS but could also be construed as 6 EMS - which is consistent with the damage data as discussed 
above. Overall, and considering the relatively poor exterior condition of many of the damaged houses, a final maximum intensity assessment of 6 EMS is a robust judgement.

\section{Spatial Extent of High Intensity Regions}

The field survey confirmed a maximum intensity of 6 EMS. Figure 11 shows the spatial extent of intensities 5 and 6 derived from the damage data when chimney damage is considered to be nonstructural, which would soon attenuate to non-damaging intensities for the rest of Folkestone (Rossetto et al., 2008). The online macroseismic survey, as shown in Figure 9, depicts intensity 6 EMS over a rather larger area, into the villages around Folkestone itself. It should be noted that online questionnaire samples are self-selecting, and therefore likely to be biased towards respondents more affected as opposed to respondents less affected. This is a well-known problem in macroseismology and is likely to be the case with all questionnaire surveys, especially online ones, which are now the majority in many countries. Note also that questionnaires can only take a simplified approach to damage; in the case of the BGS algorithm, if the respondent records partial collapse of chimneys, this is automatically considered to be grade 2 damage to class B structures.

Automatic assessment of intensity is done according to precise rules, related to the scale, which are totally objective and repeatable. In Musson (2006), the criteria for assessing 6 EMS and the other degrees are given exactly, and anyone can take these same rules, apply them and get the same result. This does mean that the algorithm does, to some extent, redefine the scale. In other words, what intensity 6 means in the context of Figure 9 is that, of the collected data, certain percentages of observers reported certain percentages of effects. Intensity is thus a property of the sample - and not necessarily of the population.

Balancing a 'true' intensity based on a correctly randomised sample of the population with a potentially biased intensity based on a sample that is not truly representative is a problematic issue that requires more depth of discussion than can be given here.

\section{DISCUSSION AND CONCLUSIONS}

Although small in world terms, the 2007 Folkestone earthquake was a remarkable event for a low seismicity country such as the UK, and all the more striking for having occurred in a highlypopulated and economically important part of the country, quite close to the capital city. It produced the highest peak ground acceleration yet recorded in the UK, and provoked the first occasion in the UK in modern times in which a local authority was obliged to institute emergency procedures and evacuate damaged buildings because of the perceived risk to the public. The worst damage was, 
however, quite restricted to a well-defined area of Folkestone. Although it is not beyond debate, it is considered that the most appropriate maximum intensity assignment is 6 EMS for this event. The spatial extent over which this and other moderate intensity levels were observed was a matter of some debate amongst the authors and is related to the interpretation of the EMS-98 scale. Some of the authors felt that further objectivity could be introduced into the scale to prevent such debates recurring in the future. It is also inevitable that as future events occur we will better appreciate how damage observed within the UK relates to the damage definitions in EMS-98.

The felt area of the earthquake was relatively small given its magnitude. This could be a regional effect; given the relatively low seismicity of SE England even by British standards, there are not many other earthquakes to compare it with. Such a conclusion would certainly be borne out by the one other easily comparable event: the 25 October 1963 Chichester earthquake, with an epicentre about $150 \mathrm{~km}$ WSW of the Folkestone event, had an instrumental magnitude of $4.7 \mathrm{M}_{\mathrm{L}}$ but a macroseismic magnitude (based on felt area) of only 4.0 $\mathrm{M}_{\mathrm{L}}$ (Musson 1994). Neither of these values are well constrained, given the period. Alternatively, it could be suggested that the shallow depth of the Folkestone earthquake was a factor; most of the more significant British earthquakes have had depths of more than $10 \mathrm{~km}$. A shallower focus means that the near-field radiation of seismic energy is confined to the uppermost, lowest velocity, part of the crust. The 1963 earthquake had a poorly constrained macroseismic depth of $12 \mathrm{~km}$.

An interesting comparison can be made between the Folkestone earthquake and the Colchester earthquake of 22 April 1884 which had an epicentre about $80 \mathrm{~km}$ NNW of Folkestone. This was the most damaging British earthquake of the last 400 years and its impact on buildings has been examined by Weston et al. $(2002,2004)$. This was another moderate magnitude shallow-focus event, in this case with a depth as shallow as about $3 \mathrm{~km}$ (Burton, 1993). Similarly to Folkestone, the near-surface focus was a significant factor in the generation of substantial damage, in a narrow area south of the town of Colchester. In view of the shallow-focus and ensuing building damage, a thorough assessment of building vulnerability was required in Colchester (Weston et al., 2004) to gain improved understanding of the impact of this earthquake and the same now remains true of the vulnerability of the Folkestone building stock. Further, while Colchester 1884 was reported widely in contemporary accounts at very low intensities due to the newsworthiness of the event, the area affected by intensities of 4 EMS and higher was very modest (Musson et al 1990), leading to a magnitude estimate of 4.6 $\mathrm{M}_{\mathrm{L}}$ (Musson 1994). If the discrepancy between instrumental and macroseismic magnitudes shown by the Folkestone earthquake is a consistent effect, then the magnitude of the 1884 earthquake should be revised upwards, perhaps to $5.0 \mathrm{M}_{\mathrm{L}}$. 


\section{ACKNOWLEDGEMENTS}

We would like to thank John Alarcón (Imperial College) for conducting some early investigations into the strong-motion record and Julian Bukits (British Geological Survey) for his assistance with the macroseismic data collection and processing. We thank Lars Ottemöller for reviewing the article. Peter Stafford is a fellow of the Willis Research Network and would like to acknowledge the generous financial support afforded to him. We would also like to thank Shepway District Council and the residents of Folkestone for their invaluable assistance during the field surveys. This work is published with the permission of the Executive Director, British Geological Survey (Natural Environment Research Council).

\section{REFERENCES}

Akkar, S. and J.J. Bommer (2007a). New empirical prediction equations for peak ground velocity derived from strong-motion records from Europe and the Middle East. Bulletin of the Seismological Society of America 97(2), 511-530.

Akkar, S., and J.J. Bommer (2007b). Prediction of elastic displacement response spectra in Europe and the Middle East. Earthquake Engineering \& Structural Dynamics 36(10), 1275-1301.

Ambraseys, N.N., K.A Simpson and J.J. Bommer (1996). The prediction of horizontal response spectra in Europe. Earthquake Engineering \& Structural Dynamics 25, 371-400.

Ambraseys, N. N., J. Douglas, S.K. Sarma, and P.M. Smit (2005). Equations for the estimation of strong ground motions from shallow crustal earthquakes using data from Europe and the Middle East: horizontal peak ground acceleration and spectral acceleration. Bulletin of Earthquake Engineering 3(1), 1-53.

Bommer, J.J., A.S. Elnashai and A.G. Weir (2000). Compatible acceleration and displacement spectra for seismic design codes. Proceedings of the $12^{\text {th }}$ World Conference on Earthquake Engineering, Paper no. 207, Auckland, New Zealand.

Bommer, J.J. and A. Martínez-Pereira (1999). The effective duration of earthquake strong motion. Journal of Earthquake Engineering 3, 127-172.

Bommer, J.J. and R. Mendis (2005). Scaling of spectral displacement ordinates with damping ratios. Earthquake Engineering \& Structural Dynamics 34(2), 145-165.

Bommer, J.J. and R. Pinho (2006). Adapting earthquake actions in Eurocode 8 for performancebased seismic design. Earthquake Engineering \& Structural Dynamics 35, 39-55. 
Bommer, J.J., P.J. Stafford, J.E. Alarcón and S. Akkar (2007). The influence of magnitude range on empirical ground-motion prediction. Bulletin of the Seismological Society of America 97(6), 2152-2170.

Bungum, H., C.D. Lindholm, A. Dahle, G. Woo, F. Nadim, J.K. Holme, O.T. Gudmestad, T. Hagberg and K. Karthigeyan (2000). New seismic zoning maps for Norway, the North Sea, and the United Kingdom. Seismological Research Letters 71(6), 687-697.

Burton, P.W. (1993). Macroseismic inversion and variation in intensity attenuation in Britain. Proceedings of the XXIII Gen. Ass. European Seismological Commission, vol.2, pp. 388-392, September 7-12, 1992, Prague.

CEN (2004). Eurocode 8, design of structures for earthquake resistance - part 1: general rules, seismic actions, and rules for buildings, EN 1998-1:2004. Comité Européen de Normalisation, Brussels.

Cotton, F., F. Scherbaum, J.J. Bommer and H. Bungum (2006). Criteria for selecting and adjusting ground-motions models for specific target regions: Applications to Central Europe and rock sites. Journal of Seismology 10, 137-156.

Dahle, A., H. Bungum and L.B. Kvamme (1990). Attenuation models inferred from intraplate earthquake recordings. Earthquake Engineering \& Structural Dynamics 19, 1125-1141.

Grünthal, G. (1998). European Macroseismic Scale 1998 EMS-98, Conseil de l'Europe, Cahiers du Centre Européen de Géodynamique et de Séismologie, Vol. 15, Luxembourg, 99 pages.

Musson, R. M. W. (1994). A catalogue of British earthquakes, British Geological Survey Global Seismology Report, WL/94/04.

Musson, R.M.W. (2002) Intensity and intensity scales, in Bormann, P. (ed) Manual of Seismological Observatory Practice, 12.1-12.20.

Musson, R.M.W. (2005). Intensity attenuation in the UK, Journal of Seismology, 9, 73-86.

Musson, R.M.W. (2006). Automatic assessment of EMS-98 intensities, British Geological Survey Technical Report IR/06/048.

Musson, R.M.W., Neilson, G., and Burton, P.W. (1990). Macroseismic reports on historical British earthquakes XIV : 22 April 1884 Colchester, BGS Seismology Report No. WL/90/33.

Musson, R.M.W., P.C. Marrow and P.W. Winter (1994). Attenuation of earthquake ground motion in the UK. AEA Technology Consultancy Services (SRD), AEA/CS/16422000/ZJ745/004

Musson, R.M.W. and P.W. Winter (1997). Seismic hazard maps for the U.K. Natural Hazards 14, 141-154.

Musson, R.M.W. and Cecić, I. (2002). Macroseismology, in Lee, W.H.K., Kanamori, H., Jennings, P.C. and Kisslinger, C. (eds) International Handbook of Earthquake and Engineering Seismology, Academic Press, San Diego. 
Ottemöller, L., Baptie, B., and Smith, N. (2008) Source parameters for the 4.0 Mw earthquake in Folkestone, UK, on 28 April 2007, submitted to BSSA.

Ove Arup, 1993. Earthquake hazard and risk in the UK, Technical Report, Ove Arup \& Partners, London.

Rey, J., E. Faccioli and J.J. Bommer (2002). Derivation of design soil coefficients (S) and response spectral shapes for Eurocode 8 using the European Strong-Motion Database. Journal of Seismology 6, 547-555.

Rossetto, T., M. Free and M. Hill (2007). Report on Building Damage from the $28^{\text {th }}$ April 2007 Kent (Folkestone) Earthquake and Intensity Evaluation. The Society for Earthquake and Civil Engineering Dynamics (SECED) Newsletter 20(3), 6-10.

Shary, P.A., L. S. Sharaya and A. V. Mitusov (2001). Fundamental quantitative methods of land surface analysis. Geoderma 107, 1-32.

Shepway District Council, 2001. Shepway District Council Private Sector House Condition Survey, Draft Final Report, Managed Series and Consultancy Limited, September, 2001.

Stafford, P.J., R. Mendis and J.J. Bommer (2008). The dependence of spectral damping ratios on duration and number of cycles. Journal of Structural Engineering - ASCE, 134(8), in press.

Toro, G.R., N.A. Abrahamson and J.F. Schneider (1997). Model of strong ground motions from earthquakes in Central and Eastern North America: Best estimates and uncertainties. Seismological Research Letters 68(1), 41-57.

Wald, D.J., Quitoriano, V., Heaton, T.H., and Kanamori, H. (1999). Relationships between peak ground acceleration, peak ground velocity, and modified Mercalli intensity in California. Earthquake Spectra 15(3), 557-564.

Wald, D.J., and Allen, T.I. (2007). Topographic slope as a proxy for seismic site conditions and amplification, Bulletin of the Seismological Society of America, 97 (5), 1379-1395.

Weston, A-J.S., Burton, P.W., Davenport, C.A. and Lovett, A.A. (2002). An earthquake impact scenarios (EIS) developed for the Colchester 1884 earthquake. CD-ROM Proceedings XXVII Gen. Ass. European Seismological Commission, Genoa, Italy, September 2002.

Weston, A-J., Lovett, A.A. and Burton, P.W. (2004). The Vulnerability of Building Stock to Seismic Hazard: a GIS-based Analysis of Colchester, UK. Proceedings GIS Research UK $21^{\text {th }}$ Annual Conference GISRUK 2004.

Zeverbergen, L. W., and Thorne.C R, (1987). Quantitative analysis of land surface topography, Earth Surface Processes and Landforms, 12, 47-56. 


\section{TABLES}

Table 1. Number of damaged properties coinciding with unconsolidated deposits for the traditional geological map and the $50 \mathrm{~m}$ accumulated material model.

\begin{tabular}{|l|c|c|c|}
\hline \multicolumn{1}{|c|}{ Geological model } & $\begin{array}{c}\text { Number of } \\
\text { properties }\end{array}$ & $\begin{array}{c}\text { Significant } \\
\text { damage } \\
\text { (Category 1-4) }\end{array}$ & $\begin{array}{c}\text { Unassessed } \\
\text { (reportedly) } \\
\text { damage }\end{array}$ \\
\hline All Property & 1326 & $778(59 \%)$ & $548(41 \%)$ \\
\hline $\begin{array}{l}\text { Properties underlain by traditionally } \\
\text { mapped superficial deposits }\end{array}$ & $165(12 \%)$ & $93(7 \%)$ & $72(5 \%)$ \\
\hline $\begin{array}{l}\text { Properties underlain by } \\
\text { accumulation model }(50 \mathrm{~m})\end{array}$ & $778(59 \%)$ & $467(35 \%)$ & $311(23 \%)$ \\
\hline
\end{tabular}


Table 2. Summary of reports of strong effects and damage from Folkestone (from questionnaire responses from the most damaged $5 \times 5 \mathrm{~km}$ square area)

\begin{tabular}{|l|c|c|c|}
\hline Effect & Yes & No & NA \\
\hline Objects shifted & 164 & 14 & 22 \\
\hline Books etc fall & 89 & 52 & 59 \\
\hline Furniture shifted & 37 & 99 & 64 \\
\hline Furniture topples over & 9 & 127 & 54 \\
\hline Small cracks in plaster & 114 & 14 & 72 \\
\hline Large cracks in plaster & 58 & 49 & 93 \\
\hline Fall of small pieces of plaster & 83 & 35 & 82 \\
\hline Fall of large pieces of plaster & 17 & 75 & 108 \\
\hline Fall of stones & 60 & 58 & 82 \\
\hline Small cracks in brickwork & 67 & 42 & 91 \\
\hline Large cracks in brickwork & 31 & 68 & 101 \\
\hline Fall of free-standing walls & 7 & 91 & 102 \\
\hline Fall of chimneys & 40 & 75 & 85 \\
\hline House walls partly collapse & 98 & 92 \\
\hline
\end{tabular}




\section{FIGURES}
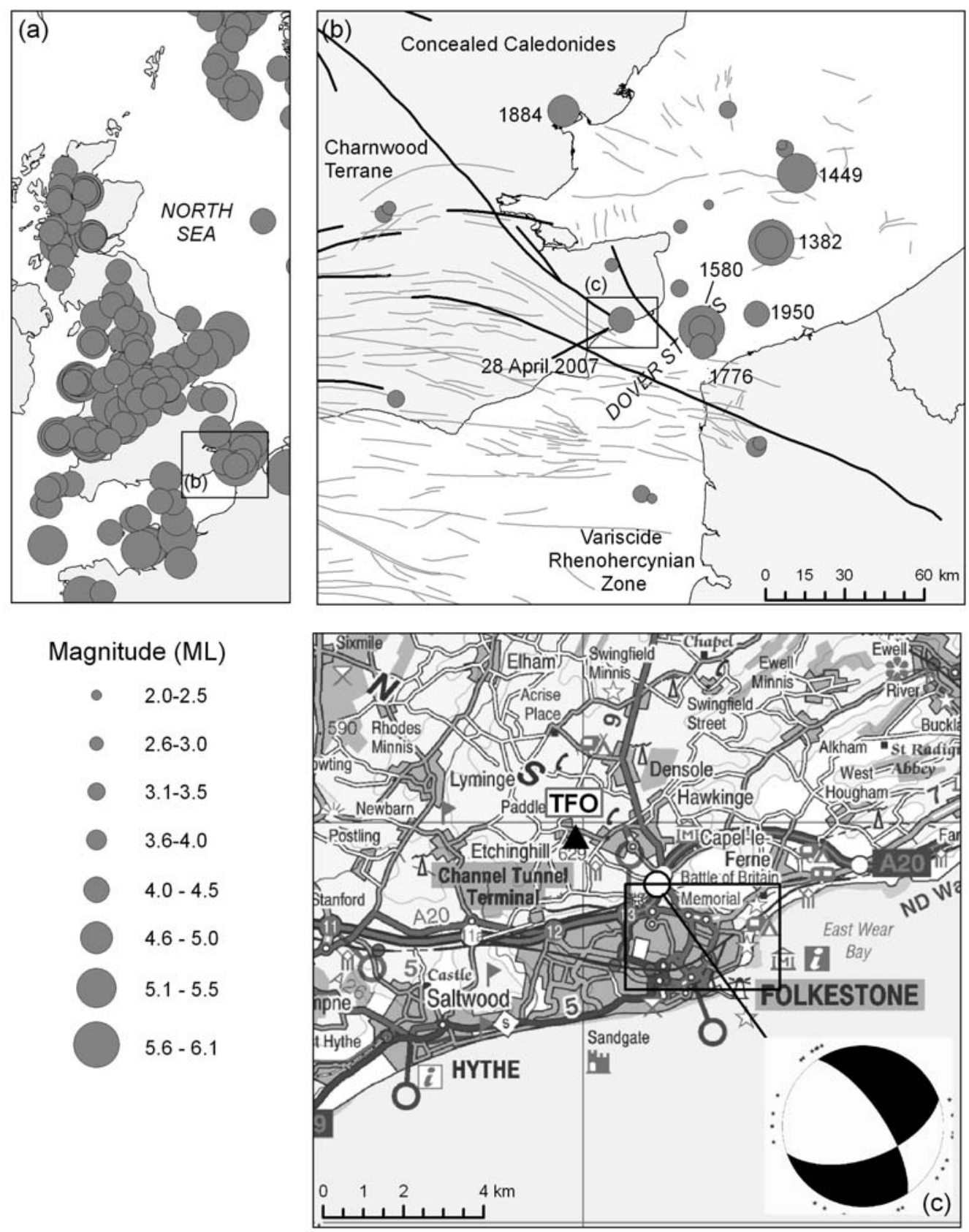

Figure 1 (a) Seismicity of the UK (ML $\geq 4)$; (b) structural and seismicity (ML $\geq 2$ ) map of southeastern England. Major structures are shown as black lines; smaller features are shown as grey lines; (c) map of the Folkestone region showing the location of TFO and the fault plane solution for the event (after Ottemöller et al., 2008). 

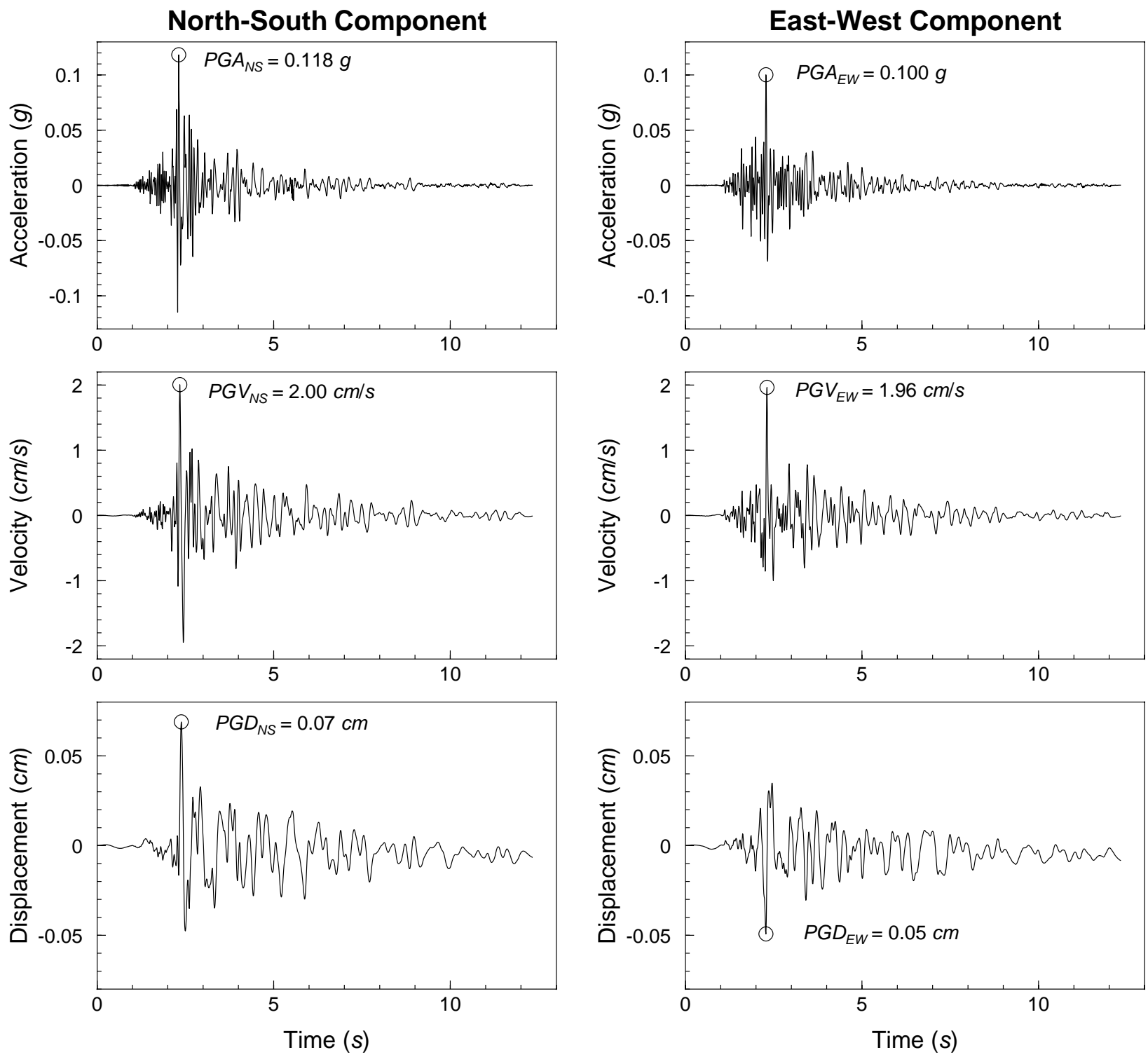

Figure 2. Horizontal acceleration, velocity and displacement time histories of the accelerogram recorded at station TFO. 


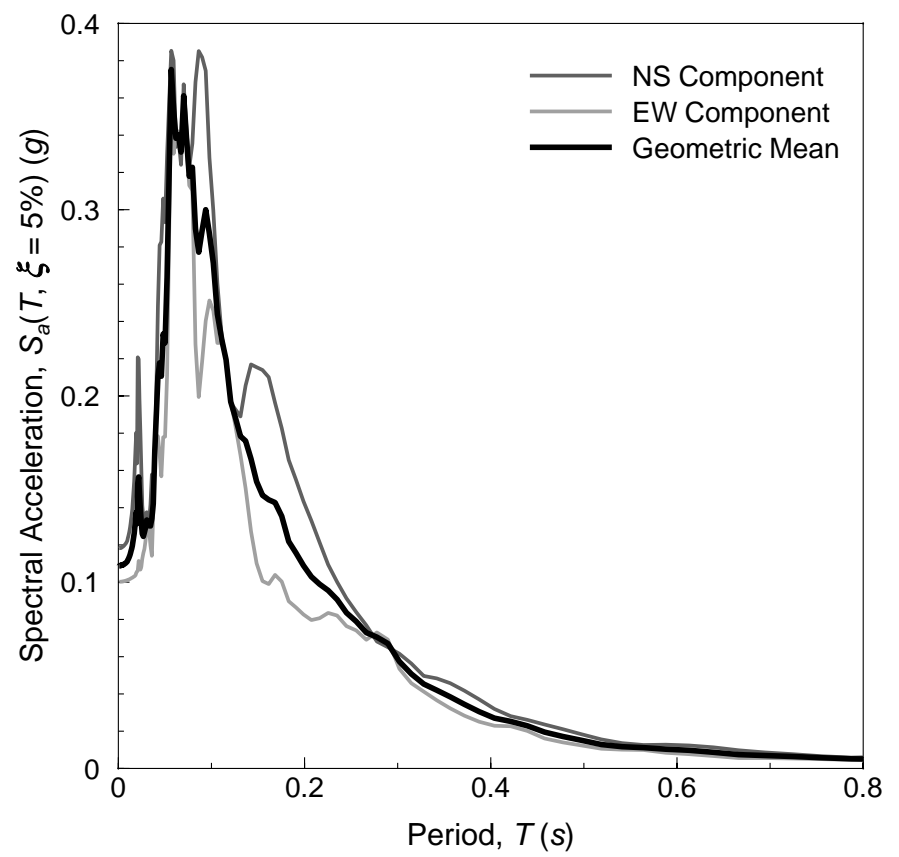

Figure 3. Elastic 5\% damped acceleration response spectra for the Folkestone recording 

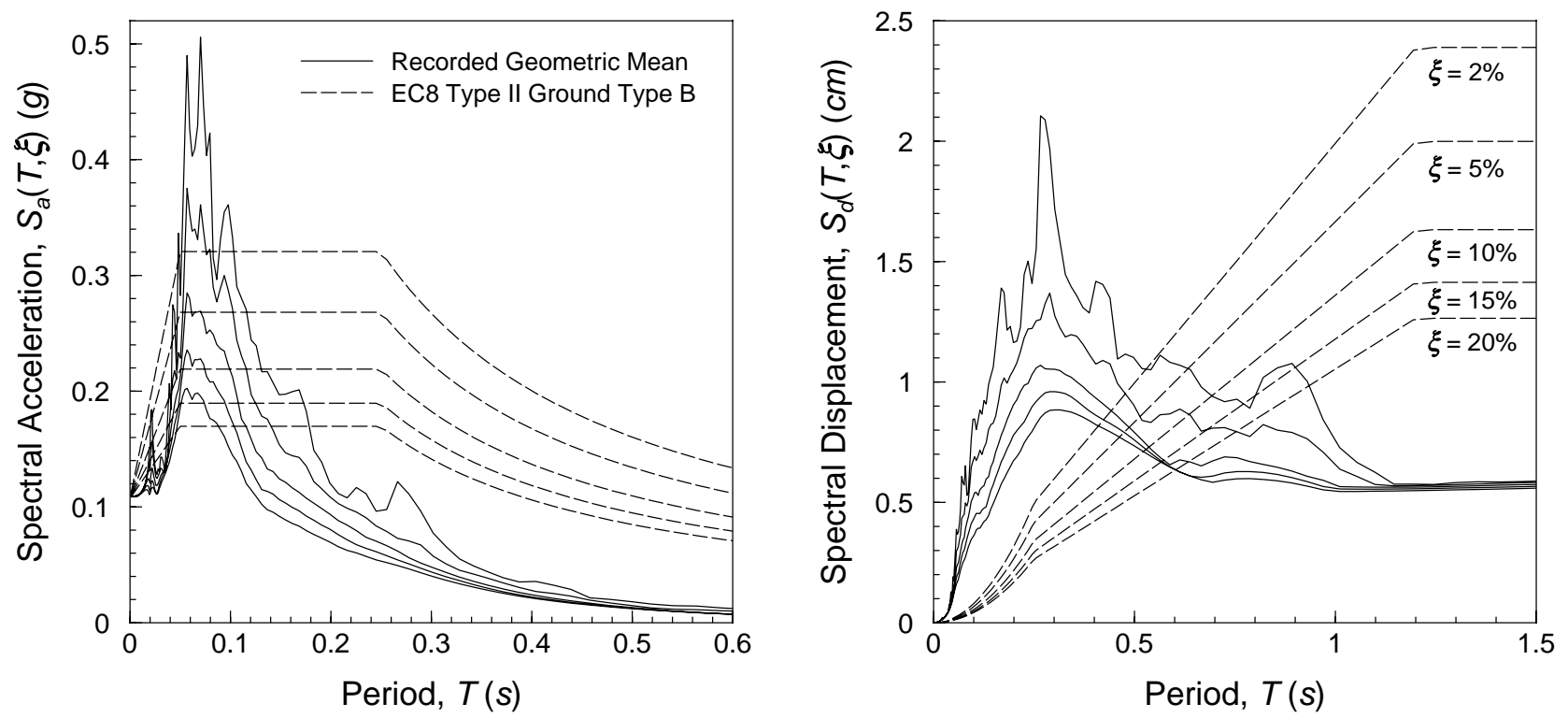

Figure 4. Comparison of the geometric mean of the recorded acceleration (left) and displacement (right) spectra at various levels of damping with the design spectra of Eurocode 8 . The recorded spectra, denoted by the solid lines, follow the same trends as the annotated dashed lines with the level of damping increasing with decreasing spectral amplitudes. 

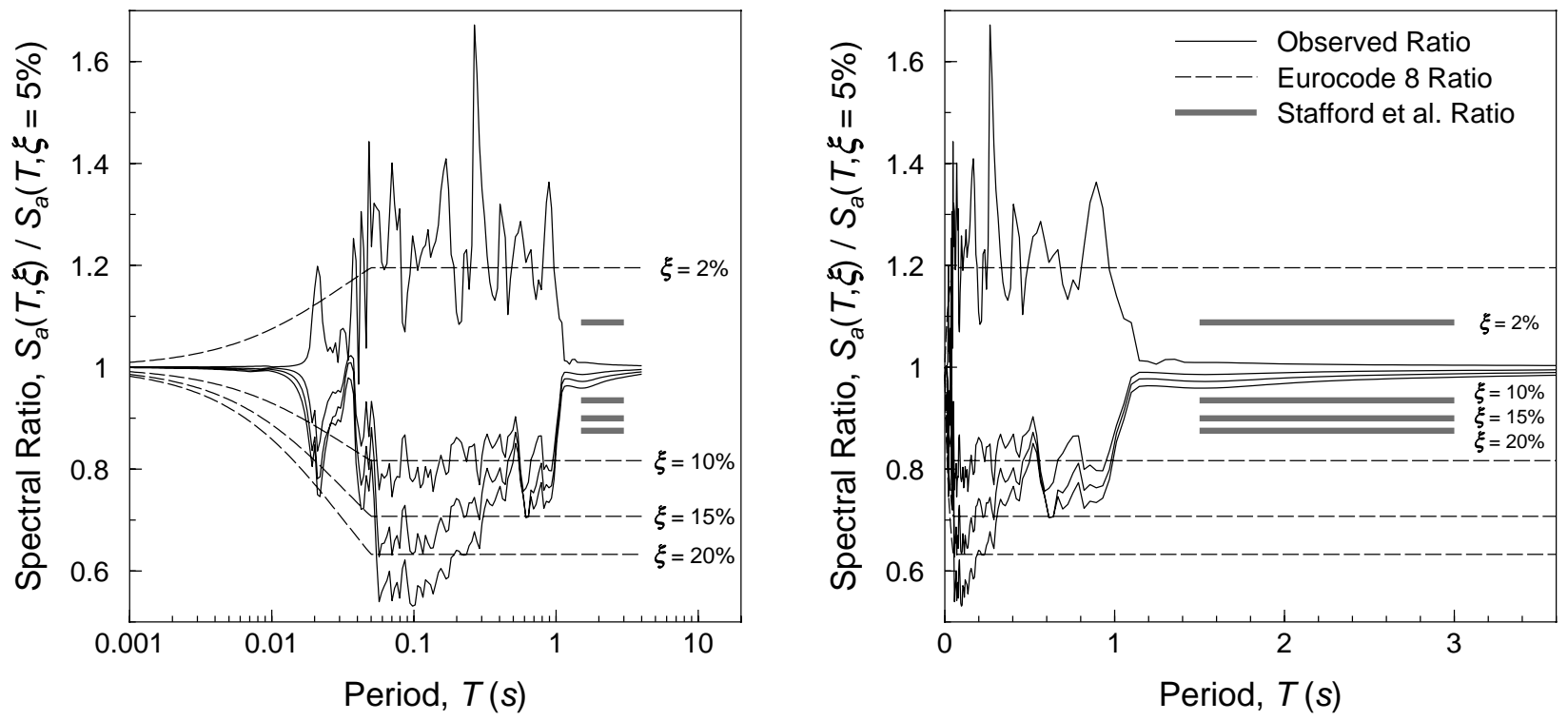

Figure 5. Comparison of the observed spectral ratios of the Folkestone recording with the damping correction factors specified in Eurocode 8 and the duration dependent ratios of Stafford et al. (2008) using the case of $D_{5-95 \%}$. The Stafford et al. (2008) relations are derived using periods between 1.5 and 3 seconds. 


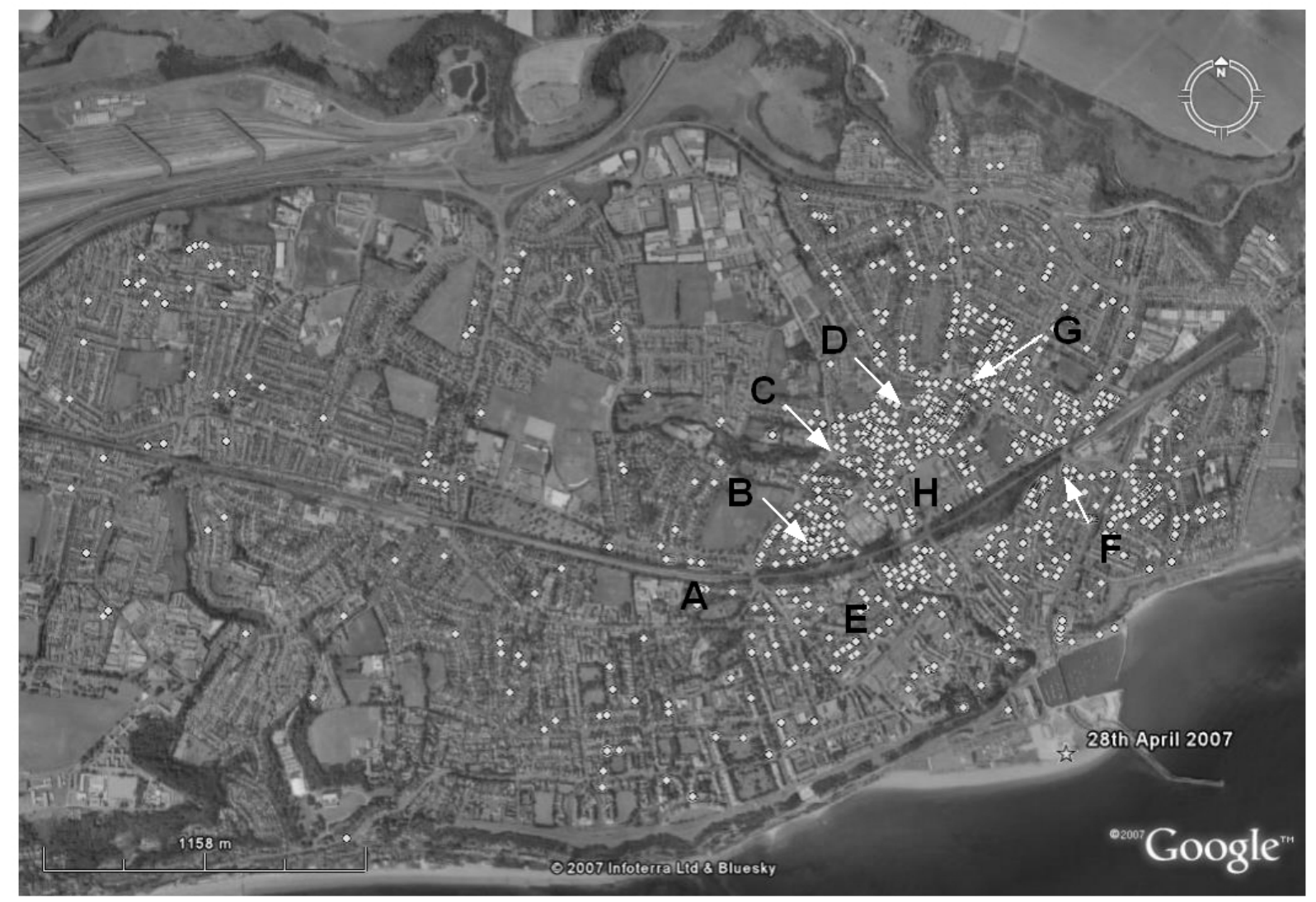

Figure 6. Map of the main areas of damage in Folkestone. Lettered locations are refered to in the text. 
a)

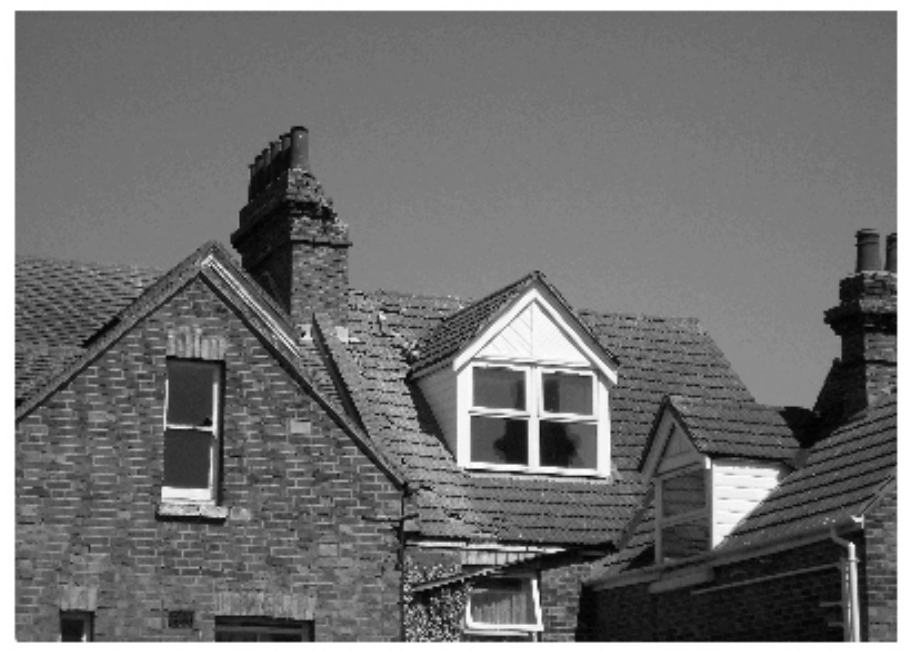

b)

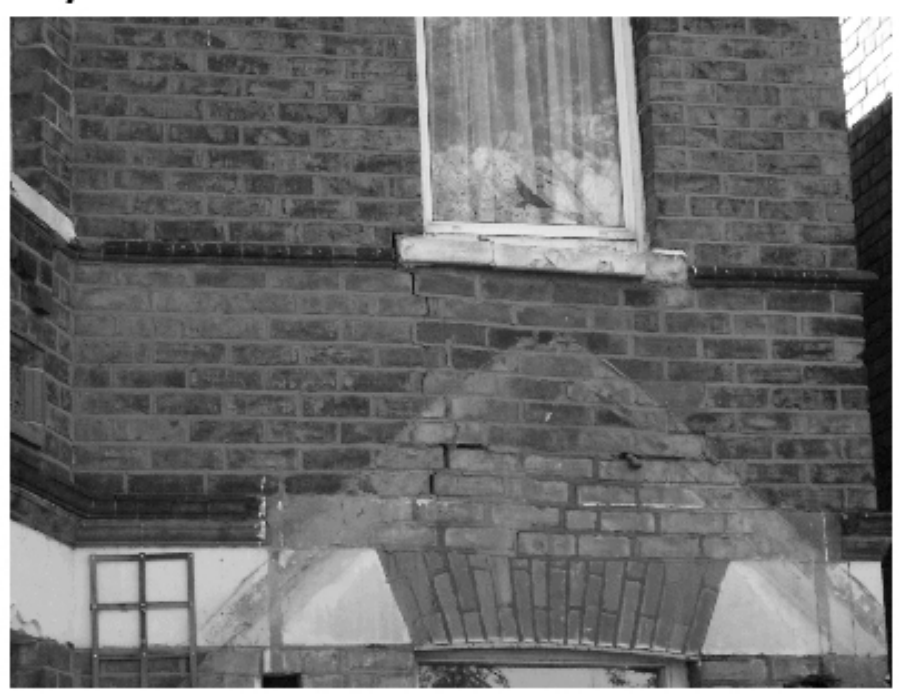

e)

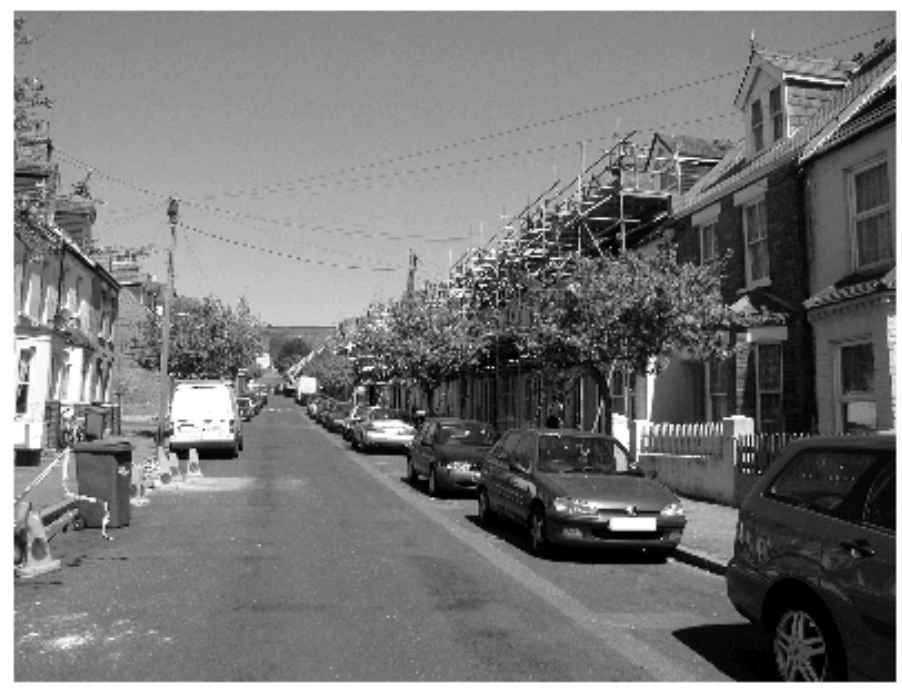

c)

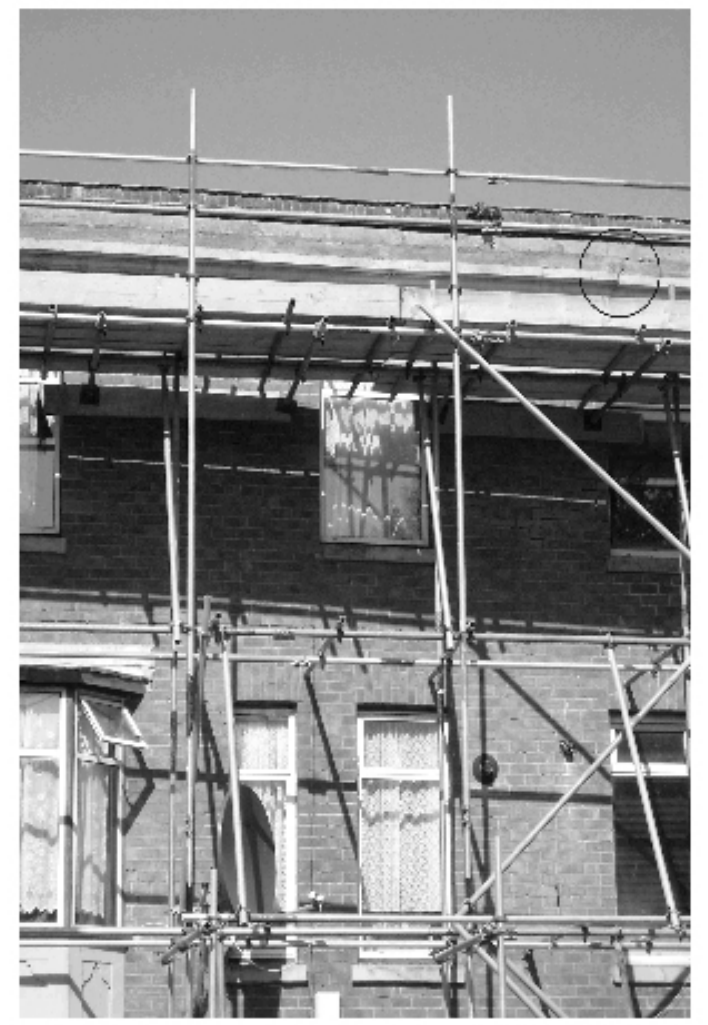

d)

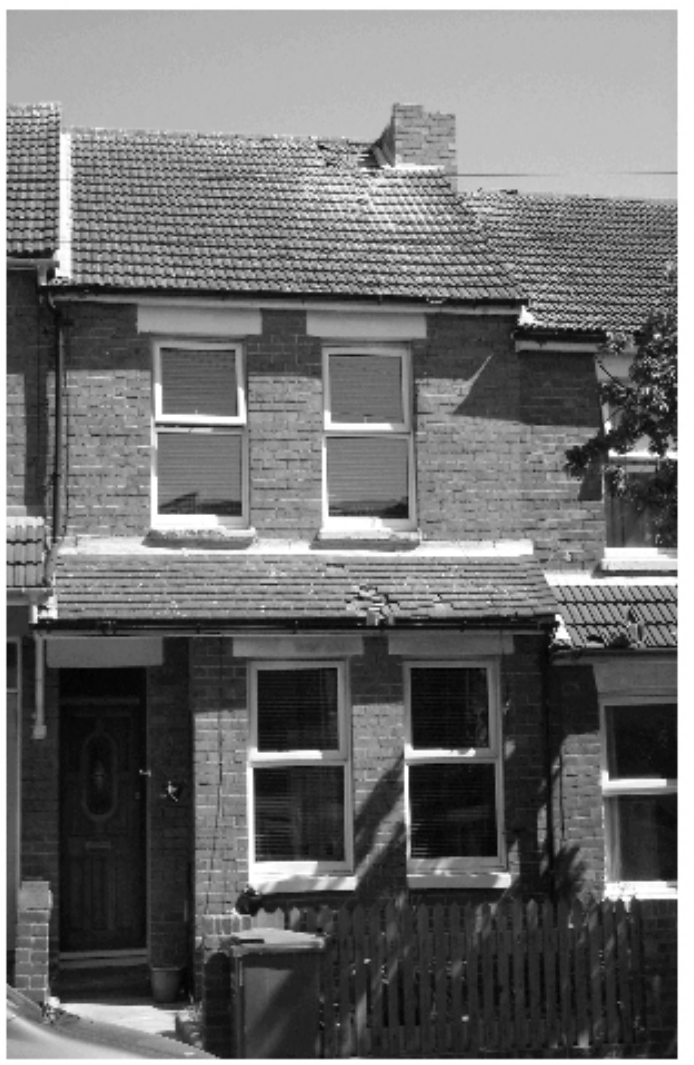

Figure 7. (a) Damaged chimneystack and secondary damage to roof tiles, (b) Cracks in brickwork (Radnor Park Road), (c) Cracks extending through the roof line of a building at Grace Hill, (d) Collapse of chimney stack to roof level and associated roof damage (Stuart Road), and (e) Marshall Street: 1930 's style terraced houses with relatively high density damage. 

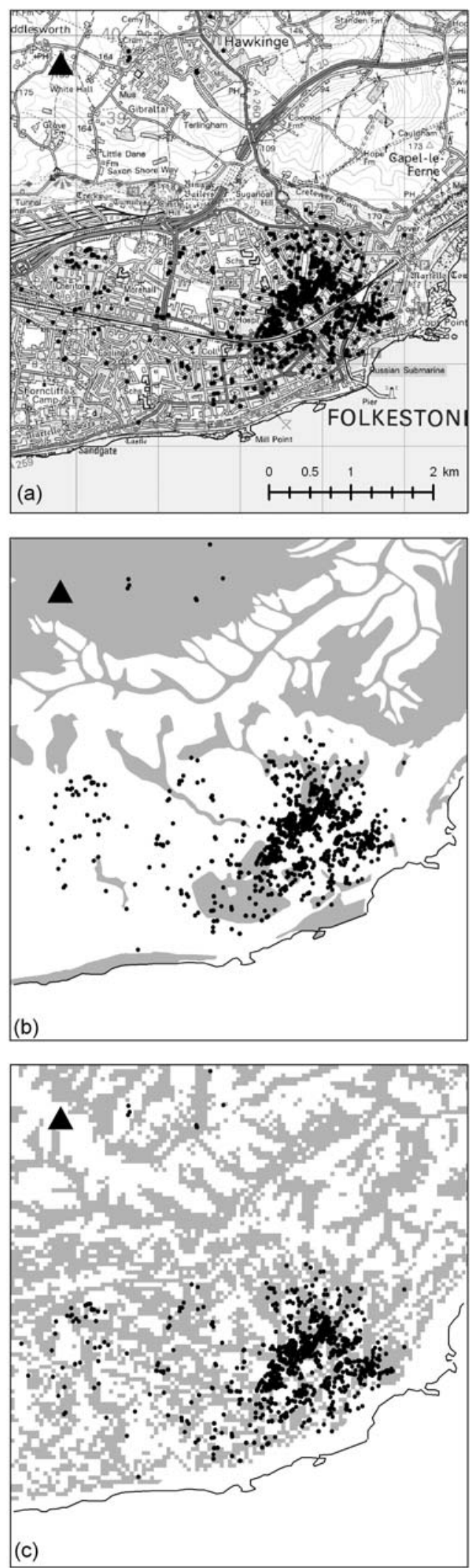

Figure 8. Damaged properties (black circles) plotted on (a) the Ordnance Survey map for Folkestone; (b) the 1:50 000 superficial geology map (mapped deposits shaded grey); (c) map showing the total curvature derived from the NDTM resampled at $50 \mathrm{~m}$. Areas of potential accumulation (negative tot $_{\text {curv }}$ ) are shaded grey. The location of TFO is denoted by the black triangle. 


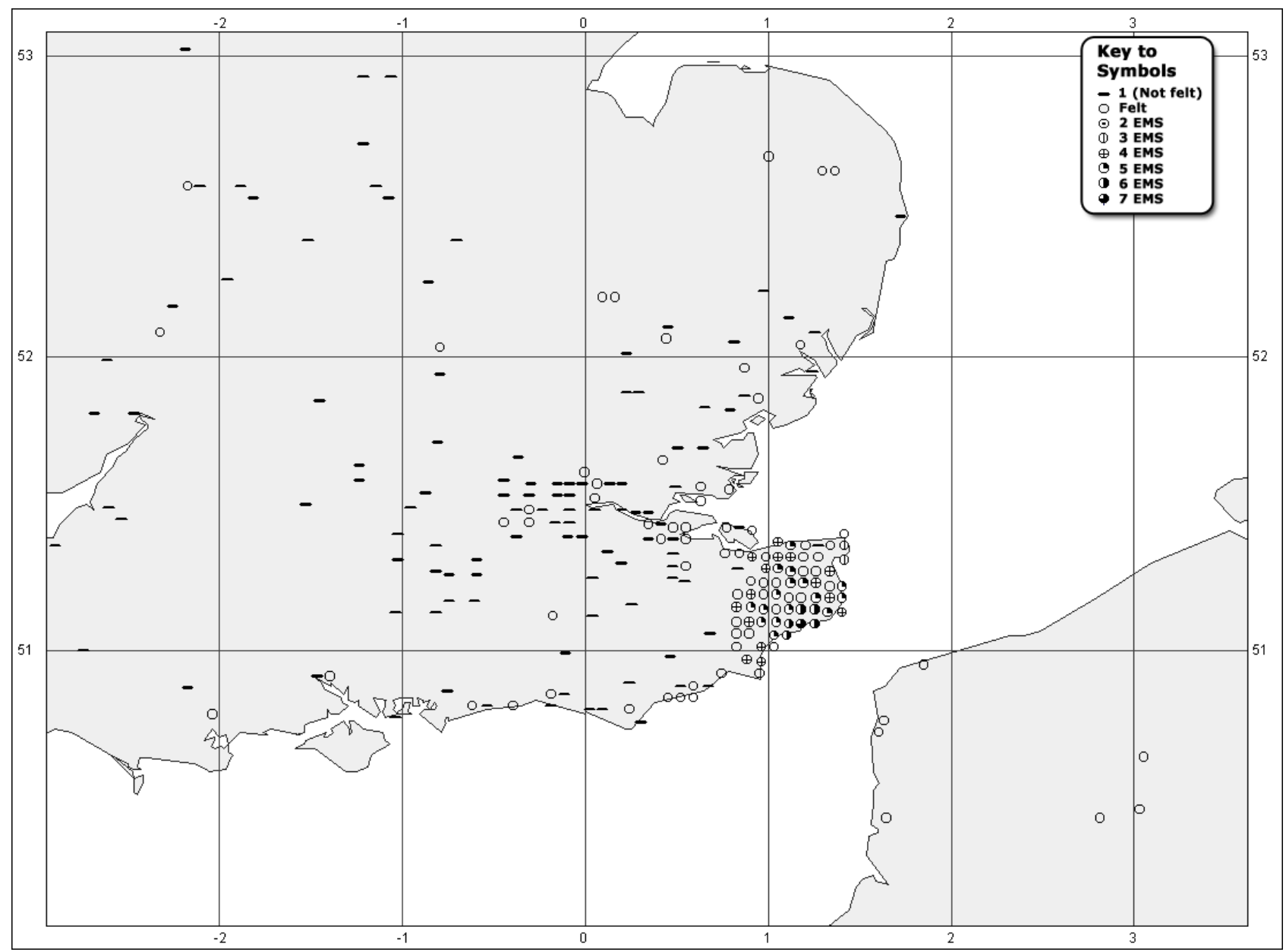

Figure 9. Distribution of intensities obtained in $5 \times 5 \mathrm{~km}$ cells through the online macroseismic survey 


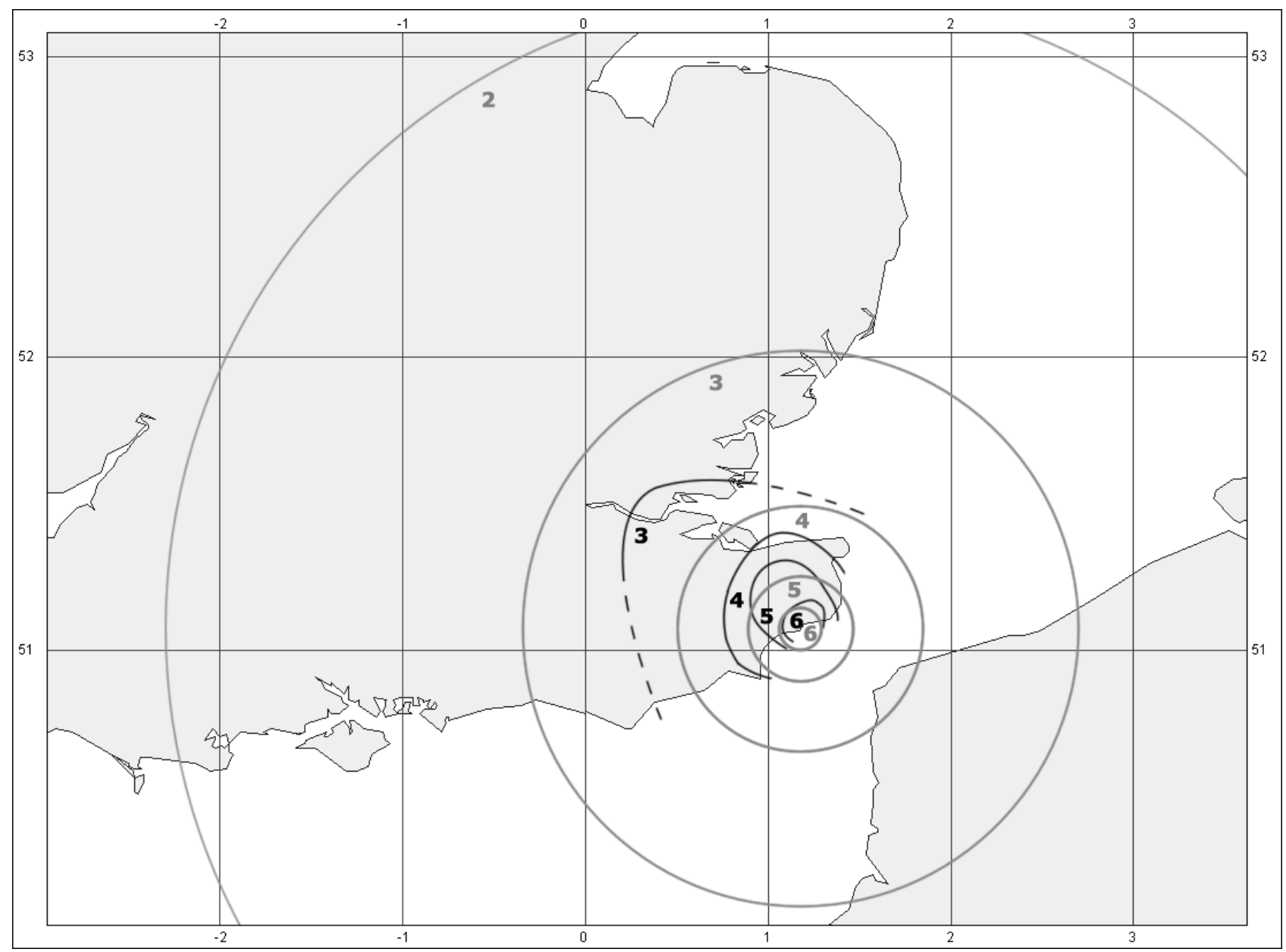

Figure 10. Observed (black lines) and modelled (grey lines) isoseismals for the Folkestone earthquake. Observed isoseismals are generated from the online macroseismic survey information presented in Figure 10 while the modelled isoseismals are obtained through the use of the Musson (2005) intensity attenuation model for the UK 


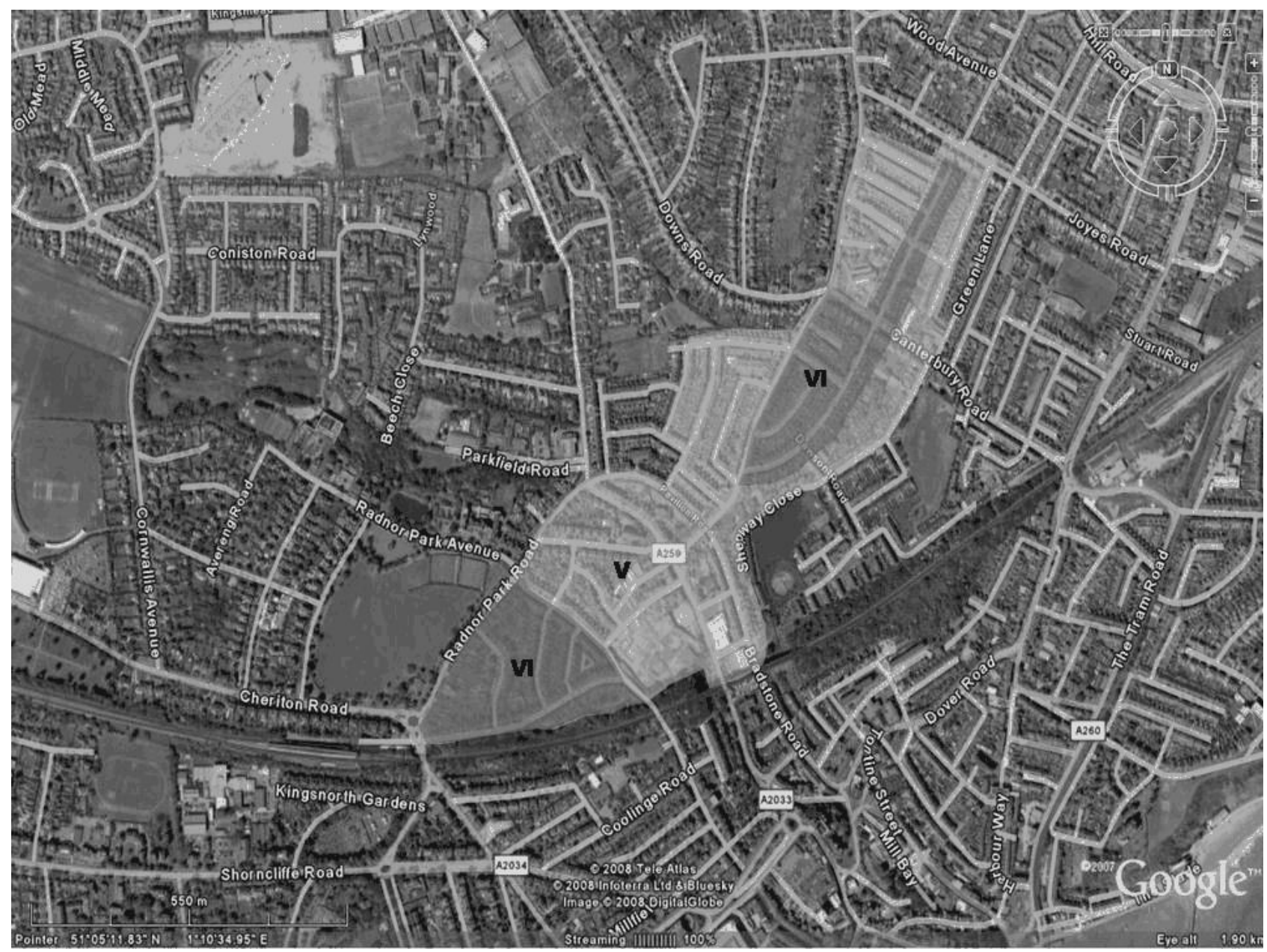

Figure 11. Map of Intensity V and VI in Folkestone derived from observations of structural damage only (assuming chimneys to be non-structural components). Intensities smaller than $\mathrm{V}$ are not plotted as these are mainly derived from observations of earthquake effects other than structural damage. 